\title{
Ward's Triangle
}

National Cancer Institute

\section{Source}

National Cancer Institute. Ward's Triangle. NCI Thesaurus. Code C122161.

A radiolucent and fracture-prone triangular zone in the proximal femur. 